TEKNIK, 39 (1), 2018, 9-15

\title{
Rancang Desain Produk Setrika Pegas Menggunakan Metode Kano
}

\author{
Anisa Nurjannah", Hari Purnomo \\ Program Studi Teknik Industri, Fakultas Teknologi Industri, Universitas Islam Indonesia \\ Jl. Kaliurang Km 14,4, Sleman, Yogyakarta, Indonesia 55584
}

\begin{abstract}
Abstrak
Pengembangan fitur-fitur setrika listrik terus dilakukan guna meningkatkan kepuasan konsumen. Penelitian ini bertujuan untuk mendesain produk setrika listrik berdasar fitur-fitur yang sesuai dengan keinginan dan kepuasan penggunanya. Fitur-fitur yang diinginkan diketahui dari wawancara dan menjadi dasar perbaikan desain setrika listrik yang telah beredar di pasaran. Output dari tahapan Voice of Customers ini kemudian dianalisa untuk dicari tingkat kepentingan tiap fitur menggunakan Metode Kano. Hasil pengolahan dengan Metode Kano menunjukkan enam fitur, dengan kategori tingkat kepuasan berupa attractive dan one-dimentional, yang sangat perlu untuk dikembangkan. Fitur-fitur tersebut adalah: aman, gagang nyaman dipegang, tahan lama, ringan, kesesuaian warna, serta hemat listrik.
\end{abstract}

Kata kunci: setrika listrik; ergonomi; Metode Kano; Voice of Customers; desain

\begin{abstract}
[Design of Springs Iron Using Kano Method] Improving electric irons has been doing for customers satisfaction. This study aimed to design electric irons based on features that meet the customers satisfaction. Features are obtained from interviews. These became the basis for the proposed improvement design of electric irons available on the market. The output of this Voice of Customers stage was then analyzed using Kano method. The result showed 6 features, that meet satisfaction level of attractive and one-dimentional which need to be developed the most. The features were: safe, comfortable handles, durable, light, matching color, and low energy consuming.
\end{abstract}

Keywords: electric irons; ergonomics; Kano method; Voice of the Customers; design

\section{Pendahuluan}

Setrika berasal dari bahasa Belanda, strijkizer, yang memiliki arti menghilangkan kerutan dari baju dengan alat yang dipanaskan. Pertama kali ditemukan pada abad 17, setrika kini mengalami perkembangan yang sangat pesat (Mardani, 2015) sehingga tidak hanya sebagai peralatan penunjang, namun menjadi kebutuhan bagi setiap orang. Tercatat pada tahun 2012 hingga 2013, penjualan setrika di Indonesia sebesar 4,7 juta unit, menempati peringkat ketiga penjualan elektronik di Indonesia setelah alat penanak nasi dan peralatan dapur (Lazuardy, 2013). Hingga saat ini, pengembangan fiturfitur setrika listrik masih terus dilakukan guna menyempurnakan desain yang telah ada sehingga dapat meningkatkan kepuasan konsumen.

Keamanan dan keselamatan dalam pemakaian setrika merupakan salah satu faktor penting dalam

\footnotetext{
${ }^{*}$ Penulis Korespondensi.

E-mail: anisa_silado@yahoo.com
}

mendesain setrika (Standar Nasional Indonesia, 2005). Bagian-bagian yang mempengaruhi keamanan pada setrika diantaranya adalah pemanas/konduktor, kabel, dudukan setrika, dan komponen-komponen penunjang lainnya. Hingga saat ini, tidak sedikit pengguna yang mengalami kecelakaan kerja saat menggunakan setrika, seperti luka bakar, tersengat listrik, tertimpa setrika, dan lain-lain. Oleh karena itu, perlu terus dilakukan penelitian guna memperoleh desain setrika yang aman digunakan, sehingga angka kecelakaan kerja saat menyetrika dapat berkurang.

Wee (2014) berhasil mendesain setrika hemat listrik dan aman digunakan. Penghematan energi listrik dilakukan dengan sistem kontrol manual dan otomatis menggunakan thermostat control. Fitur keamanan diperhatikan dengan merancang desain 2 sisi simetris. Penelitian ini dimaksudkan untuk membuat desain setrika yang sesuai dengan keinginan pengguna. Berbeda dengan penelitian yang dilakukan oleh Wee (2014), pada penelitian ini fitur yang akan dikembangkan ditentukan 


\section{TEKNIK, 39 (1), 2018, 10}

berdasarkan Voice of Customers. Namun demikian, tidak semua atribut/fitur yang dijaring melalui Voice of Customers dapat dikembangkan, melainkan hanya fiturfitur yang dapat dapat meningkatkan kepuasan konsumen saja. Terkait dengan kepuasan konsumen, penelitian ini menggunakan metode Kano. Metode Kano merupakan salah satu model yang dapat digunakan untuk mengkategorikan atribut suatu produk/jasa dalam memuaskan pelanggan (Haryono \& Bariyah., 2014). Alasan pemilihan metode Kano karena dengan menggunakan metode ini, akan dapat diketahui tingkat urgensi dari masing-masing Voice of Customers, sehingga dapat diambil tindakan/keputusan sesuai dengan tingkat prioritas pada hasil yang didapat. Terdapat 5 (lima) jenis atribut produk yang memiliki hubungan dengan kepuasan pelanggan, yaitu Must-Be, Attractive, Indifferent, OneDimentional, dan Reserve (Rashid dkk., 2011). Dari hasil wawancara, diperoleh berbagai atribut/fitur setrika yang diinginkan oleh pengguna. Selanjutnya, seluruh atribut tersebut menjadi input dalam aplikasi metode Kano. Atribut/fitur dengan tipe Attractive akan menjadi fokus pada penelitian ini karena jika fitur tersebut dikembangkan, maka kepuasan pelanggan akan sangat meningkat (Paraschivescu, 2012).

\section{Metode Penelitian}

\subsection{Objek Penelitian}

Objek pada penelitian ini adalah setrika listrik pegas, yaitu setrika yang menggunakan pegas serta adanya tekanan untuk dapat menggerakkan alas setrika listrik. Selain adanya tambahan pegas sebagai penggerak alas, setrika ini juga memiliki fitur/atribut penunjang seperti gagang setrika yang nyaman digenggam, keunggulan dalam pemilihan bahan, kesesuaian warna, serta hemat listrik.

\subsection{Subjek Penelitian}

Subjek pada penelitian ini adalah pengguna setrika di wilayah Sidikan Umbulharjo Yogyakarta, dengan jenis kelamin wanita pada usia produktif 20 hingga 40 tahun, yang berprofesi sebagai ibu rumah tangga, karyawan, dan mahasiswa. Jumlah populasi sebesar 47 orang dan tingkat kepercayaan 90\%, menggunakan rumus dari Slovin (Taifa \& Desai, 2016), maka jumlah responden yang diperlukan adalah:

$n=\frac{N}{1+N \theta^{2}} \ldots \ldots \ldots . .$.
$n=\frac{47}{1+(47)(0.1)^{2}}$

$n=31,97 \sim 32$

doi: 10.14710/teknik.v39n1.13495

\subsection{Prosedur Penelitian}

\subsubsection{Mengumpulkan Voice Of Customer}

Peneliti melakukan wawancara kepada seluruh responden untuk mengetahui tanggapan dan usulan terhadap produk setrika listrik yang telah beredar di pasar. Hasil wawancara menjaring 56 macam keinginan konsumen, yang kemudian disaring untuk mendapatkan kata yang memiliki kesamaan makna dan diperoleh 10 macam Voice of Customer.

\subsubsection{Metode Kano}

Kuesioner dibuat dengan jenis pertanyaan yang saling bertentangan, yaitu bagaimana pendapat konsumen jika dibuat suatu fitur (positif) dan bagaimana jika fitur tersebut tidak dibuat (negatif). Tingkat kepentingan atau kepuasan untuk masing-masing pertanyaan adalah sama, yaitu nilai 1 (satu) untuk respon sangat suka, 2 (dua) untuk suka, 3 (tiga) untuk netral, 4 (empat) untuk tidak suka, dan 5 (lima) untuk respon sangat tidak suka.

Pada tahap evaluasi, hasil kuesioner dimasukkan ke dalam tabel evaluasi Kano. Pertanyaan positif dimasukkan dalam tabel fungsional sedangkan pertanyaan negatif dimasukkan ke dalam tabel disfungsional. Tabel 1 menunjukkan contoh tabel evaluasi Kano yang digunakan oleh Rashid dkk., (2011).

Tabel 1. Tabel Evaluasi Kano

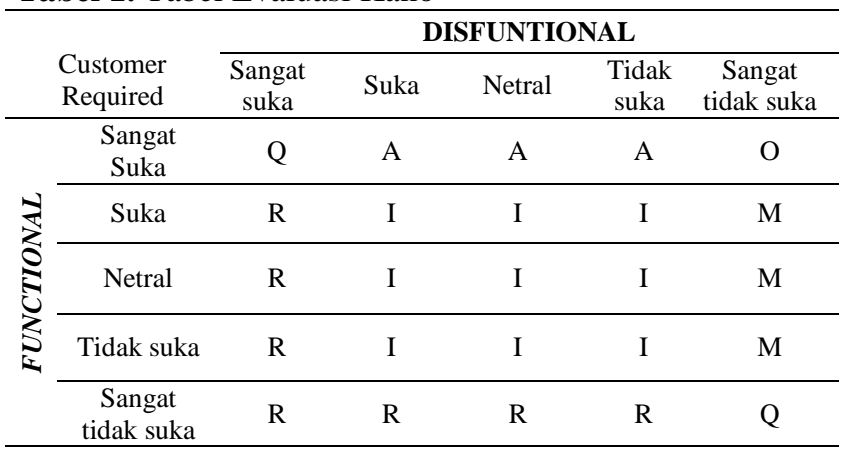

\section{Keterangan:}

a. M: Must be

b. $O$ : One dimentional

c. A: Attractive

d. I : Indifferent

e. R: Reserve

f. Q: Questionable

Interpretasi hasil kemudian dilakukan dengan menggunakan rumus (Liu., 2012):

Satisfaction $=\frac{\mathrm{A}+\mathrm{O}}{\mathrm{A}+\mathrm{O}+\mathrm{M}+\mathrm{I}}$
Disatisfaction $=-\frac{\mathrm{M}+\mathrm{O}}{(\mathrm{A}+\mathrm{D}+\mathrm{M}+\mathrm{D})}$. 


\section{TEKNIK, 39 (1), 2018, 10}

Hasil perhitungan menggunakan rumus (2) dan (3), menunjukkan tingkat kepentingan serta tingkat kepuasan konsumen terhadap suatu fitur produk.

\section{Hasil dan Pembahasan}

Sepuluh macam Voice of Customers diperoleh dari proses penyaringan seluruh tanggapan dan keinginin responden. Setiap atribut/fitur dari Voice of Customers dijabarkan menjadi butir pertanyaan pada Kano's Questioner. Hasil dari kuestioner ini dimasukkan ke dalam Kano evaluation table dan dilakukan perhitungan untuk mengetahui tingkat satisfaction (kepuasan) dan dissatisfaction (ketidakpuasan). Hasil dari proses tersebut dijabarkan pada tabel 2. Dalam penentuan kategori Kano, digunakan Blauth's formula (Dwirini, Rohayati dan Fashanah, 2015) dengan ketentuan:

1. Jika jumlah nilai $(\mathrm{A}+\mathrm{M}+\mathrm{O})>$ jumlah nilai $(\mathrm{I}+\mathrm{R}+\mathrm{Q})$ maka dipilih nilai tertinggi dari $\mathrm{A}, \mathrm{M}$, atau $\mathrm{O}$.

2. Jika jumlah nilai $(\mathrm{A}+\mathrm{M}+\mathrm{O})<$ jumlah nilai $(\mathrm{I}+\mathrm{R}+\mathrm{Q})$ maka dipilih nilai tertinggi dari I, R, atau $\mathrm{Q}$.

3. Jika jumlah nilai $(\mathrm{A}+\mathrm{M}+\mathrm{O})=$ jumlah nilai $(\mathrm{I}+\mathrm{R}+\mathrm{Q})$ maka dipilih nilai tertinggi dari A, M, O, I, R, Q.

Tabel 2. Kategori Kano

\begin{tabular}{|c|c|c|c|c|c|c|c|c|c|c|c|}
\hline $\begin{array}{c}\text { Kansei } \\
\text { Word }\end{array}$ & $\mathbf{A}$ & $\mathbf{M}$ & $\mathbf{O}$ & I & $\mathbf{R}$ & $\mathbf{Q}$ & $\mathbf{S}$ & D & $\begin{array}{c}\text { A+ } \\
\text { M } \\
+ \\
\text { O } \\
\end{array}$ & $\begin{array}{c}\mathbf{I} \\
+\mathbf{R} \\
+\mathrm{Q}\end{array}$ & $\begin{array}{c}\text { Ka } \\
\text { Te } \\
\text { Go } \\
\text { ri } \\
\end{array}$ \\
\hline Ringan & 10 & 5 & 7 & 10 & & & 0,53 & $\overline{-}, 38$ & 22 & 10 & A \\
\hline Aman & 10 & 2 & 12 & 8 & & & 0,69 & $\overline{-}, 44$ & 24 & 8 & $\mathrm{O}$ \\
\hline $\begin{array}{l}\text { Bentuk } \\
\text { Flexible }\end{array}$ & 8 & 3 & 2 & 19 & & & 0,31 & - & 13 & 19 & I \\
\hline $\begin{array}{l}\text { Gagang } \\
\text { nyaman } \\
\text { digeng } \\
\text { gam }\end{array}$ & 8 & 4 & 8 & 12 & & & 0,50 & $\overline{-}, 38$ & 20 & 12 & $\begin{array}{c}\text { A/ } \\
\text { O }\end{array}$ \\
\hline Praktis & 8 & 4 & 3 & 17 & & & 0,34 & $\overline{-}, 22$ & 15 & 17 & I \\
\hline Unik & 5 & 4 & 2 & 20 & 1 & & 0,23 & $\overline{-}, 19$ & 11 & 21 & I \\
\hline $\begin{array}{l}\text { Kesesu- } \\
\text { aian } \\
\text { warna }\end{array}$ & 11 & 4 & 2 & 15 & & & 0,41 & $\begin{array}{c}- \\
0,19\end{array}$ & 17 & 15 & A \\
\hline $\begin{array}{l}\text { Tanpa } \\
\text { Kabel }\end{array}$ & 6 & 3 & 6 & 17 & & & 0,38 & $\overline{0,28}$ & 15 & 17 & I \\
\hline $\begin{array}{l}\text { Tahan } \\
\text { Lama }\end{array}$ & 8 & 7 & 9 & 8 & & & 0,53 & $\begin{array}{c}- \\
0,50\end{array}$ & 24 & 8 & $\mathrm{O}$ \\
\hline $\begin{array}{l}\text { Hemat } \\
\text { Listrik }\end{array}$ & 9 & 5 & 7 & 11 & & & 0,50 & $\begin{array}{c}- \\
0,38 \\
\end{array}$ & 21 & 11 & A \\
\hline
\end{tabular}

\footnotetext{
Keterangan:

1. Ringan

2. Aman

3. Bentuk flexible

4. Gagang nyaman digenggam

5. Praktis

6. Unik

7. Kesesuaian warna
}

\author{
8. Tanpa kabel \\ 9. Tahan lama \\ 10. Hemat listrik
}

Merujuk hasil kategori Kano yang diperoleh pada Tabel 2, diperoleh atribut yang akan dikembangkan, dengan ketentuan: (1) atribut dengan kategori Indifferent akan diabaikan, karena ada atau tidak ada fitur tersebut tidak akan menambah kepuasan pelanggan, (2) dipilih fitur dasar yang harus ada dalam sebuah produk yaitu dengan kategori Must-Be, (3) menentukan atribut yang memiliki kategori One-dimentional karena jika fitur tersebut ada, maka pelanggan akan merasa puas dan jika fitur tersebut tidak ada, maka pelanggan akan kecewa, serta (4) atribut dengan kategori Attractive, karena sangat membantu dalam meningkatkan kepuasan pelanggan. Penyertaan fitur ini akan meningkatkan kepuasan konsumen, namun kepuasan pelanggan tidak akan menurun jika fitur tersebut tidak ada. Tingkatan ini sering disebut sebagai fitur di luar ekspektasi konsumen (Haryono dan Bariyah., 2014). Mengacu pada ketentuan tersebut, diketahui bahwa pada penelitian ini tidak ditemukan atribut dengan kategori Must-Be.

Perhitungan satisfaction dan dissatisfaction digunakan untuk menginterpretasikan atau mengetahui letak kepuasan suatu fitur dalam bentuk grafik interpretasi Kano. Fitur yang berada pada kuadran attractive dan onedimentional memiliki nilai Satisfaction yang besar, yaitu dengan nilai antara 0,5 sampai dengan 1. Dengan nilai sebesar ini, maka maka fitur inilah yang menjadi fitur utama yang perlu untuk dibuat. Gambar 1 menunjukkan grafik interpretasi dari perhitungan yang telah dilakukan.

Gambar 1 menunjukkan posisi masing-masing atribut/fitur dalam tingkat kepuasan pelanggan. Dari gambar tersebut diperoleh atribut yang berada pada kuadran atractive dan one-dimentional adalah atribut aman, ringan, hemat listrik, gagang nyaman digenggam, tahan lama, dan kesesuaian warna. Ke-6 atribut akan digunakan sebagai desain perbaikan atau usulan produk setrika. Tabel 3 merupakan tabel hubungan antar atribut dengan usulan perbaikan yang akan dilakukan.

Desain perbaikan pada atribut keamanan, konduktor atau lempengan alas setrika dibuat dengan sistem yang dapat digerakkan (naik dan turun) dengan menggunakan pegas tekan sebagai komponen tambahan. Setrika dibuat dengan lempengan konduktor yang berada di dalam kerangka luar setrika dan pergerakkan lempengan dikendalikan oleh tekanan pada pegas. Saat mendapat tekanan, konduktor setrika akan turun dari posisi awal/normal, sehingga lempengan penghantar panas akan berada sejajar dengan kerangka luar setrika. Pada saat tidak mendapatkan tekanan, alas setrika akan berada menggantung atau berada di atas kerangka luar setrika. Dengan cara kerja ini, setrika menjadi lebih aman karena penghantar panas hanya akan mengenai benda saat 


\section{TEKNIK, 39 (1), 2018, 10}

diberi tekanan dan berada pada posisi yang semestinya (menghadap ke bawah). Pengguna akan bersentuhan dengan setrika hanya dengan bagian kerangka luar setrika yang didesain terbuat dari bahan yang tidak dapat menghantarkan panas (isolator). Dengan demikian, setrika akan selalu aman baik saat terdapat aliran listrik maupun saat tidak digunakan.

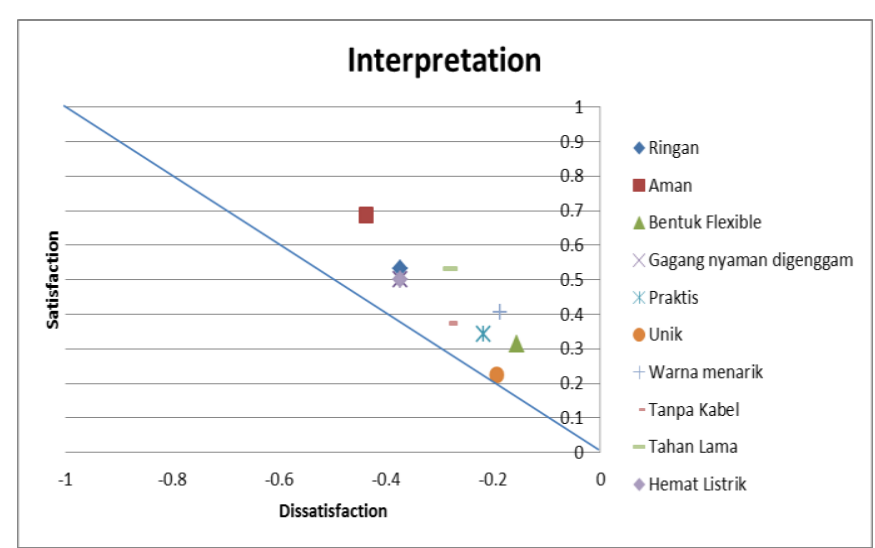

Gambar 1. Grafik Interpretasi Kano

Tabel 3. Detail Perbaikan

\begin{tabular}{|c|c|c|c|}
\hline Atribut & Kategori & $\begin{array}{c}\text { Fokus } \\
\text { Perbaikan }\end{array}$ & $\begin{array}{c}\text { Spesifikasi desain } \\
\text { usulan }\end{array}$ \\
\hline Aman & $\mathrm{O}$ & Alas luar & $\begin{array}{l}\text { Sistem naik turun } \\
\text { menggunakan pegas }\end{array}$ \\
\hline $\begin{array}{l}\text { Gagang } \\
\text { nyaman } \\
\text { digenggam }\end{array}$ & $\mathrm{O} / \mathrm{A}$ & $\begin{array}{l}\text { Gagang } \\
\text { setrika }\end{array}$ & $\begin{array}{l}\text { Ukuran panjang gagang } \\
=88,2 \mathrm{~mm} \text { dan diameter } \\
\text { gagang }=27,9 \mathrm{~mm}\end{array}$ \\
\hline $\begin{array}{l}\text { Tahan } \\
\text { Lama } \\
\text { Ringan }\end{array}$ & A & Material & $\begin{array}{l}\text { Aluminium sebagai } \\
\text { isolator, ebonit/plastik } \\
\text { sebagai kerangka setrika }\end{array}$ \\
\hline $\begin{array}{l}\text { Kesesuaian } \\
\text { warna }\end{array}$ & A & Visual & Warna tidak mencolok \\
\hline $\begin{array}{l}\text { Hemat } \\
\text { Listrik }\end{array}$ & A & Aplikasi & Kontrol suhu otomatis \\
\hline
\end{tabular}

Untuk membuat desain setrika dengan gagang yang nyaman saat digenggam, aspek ergonomi digunakan untuk menentukan ukuran gagang yang sesuai dengan dimensi tubuh manusia. Ukuran dimensi tubuh diperoleh dari penelitian yang dilakukan oleh Purnomo (2014) dengan subjek 80 responden wanita rentang usia 18 hingga 22 tahun di wilayah Kabupaten Sleman, Yogyakarta. Untuk panjang gagang setrika, digunakan dimensi tubuh lebar telapak tangan dengan persentil 95th yaitu sebesar $88,2 \mathrm{~mm}$. Alasan penggunaan persentil 95 adalah ukuran ini tetap bisa dipakai oleh manusia dengan ukuran lebar telapak tangan berukuran besar, dan tidak menimbulkan masalah jika digunakan oleh manusia dengan lebar telapak tangan berukuran kecil. Sedangkan untuk diameter gagang diperoleh dari dimensi tubuh diameter genggam maksimum dengan persentil 5 th yaitu sebesar 27,9 cm. Alasan penggunakan persentil 5 adalah dengan gagang ini sangat sesuai untuk pengguna dengan diameter genggam kecil, dan tidak menjadi masalah jika digunakan oleh manusia yang memiliki diameter genggam ukuran rata-rata maupun ukuran besar. Gambar 2 adalah desain untuk part gagang setrika listrik sesuai ukuran yang telah ditentukan.

Atribut tahan lama dan ringan berfokus pada pemilihan material yang digunakan dalam perancangan setrika pegas. Bagian setrika yang berpengaruh pada kedua atribut tersebut adalah bahan pada kerangka luar dan logam alas pada setrika yang berfungsi sebagai penghantar panas. Bahan untuk kerangka setrika didesain menggunakan ebonit dengan keunggulan ringan, kuat, ketahanan terhadap tekanan, tahan terhadap listrik, serta tahan terhadap bahan kimia yang bersifat korosif (Rubber Santo, 2017). Sedangkan untuk penghantar panas digunakan aluminimium yang memiliki keunggulan ringan, kuat, konduktor yang baik, murah, dan mudah dalam proses pengolahannya (Metal Supermarket, 2014).

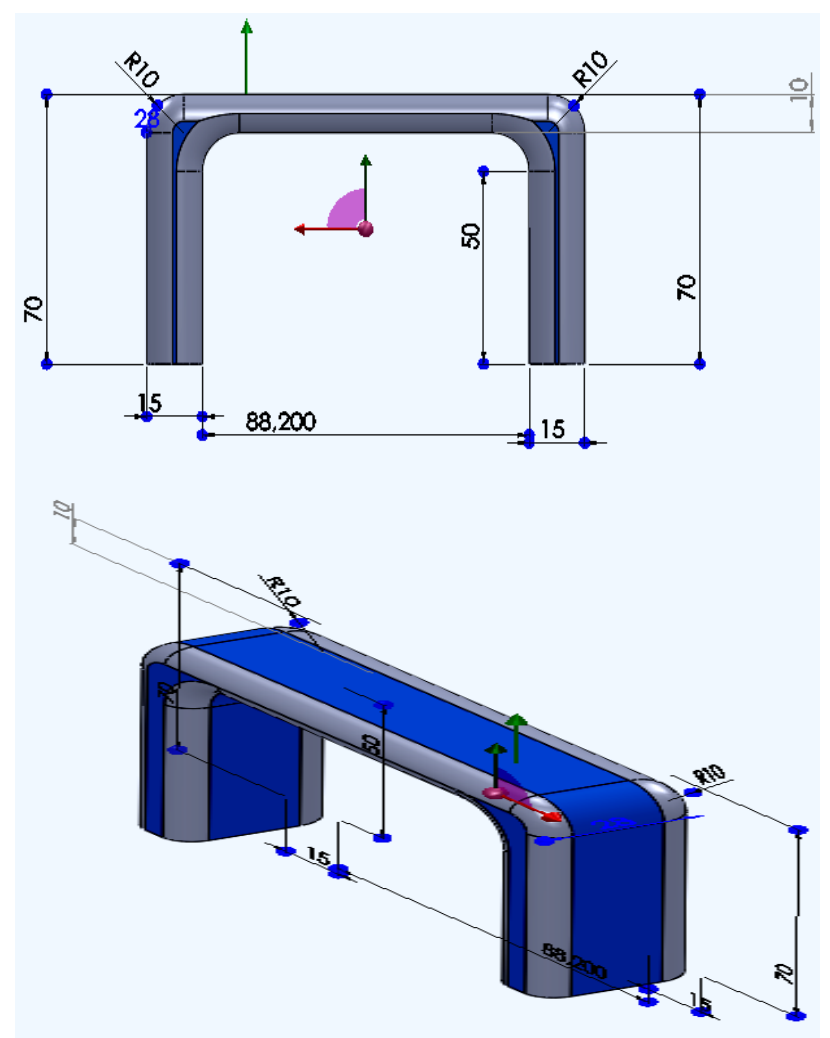

Gambar 2. Gagang Setrika

Setrika merupakan alat rumah tangga yang hanya digunakan oleh orang dewasa dan didesain untuk tidak digunakan oleh anak-anal (Standar Nasional Indonesia, 2005). Maka dari itu pemilihan warna yang sebaiknya digunakan adalah warna-warna yang tidak mencolok. Tujuannya adalah agar tidak menarik perhatian anak-anak dan orang dewasa tetap nyaman menggunakannya. 


\section{TEKNIK, 39 (1), 2018, 10}

Warna-warna yang dapat digunakan antara lain biru (memberikan efek menenangkan, kesan profesional dan kekuatan), hijau (membantu seseorang pada kondisi tertekan/banyak pekerjaan untuk dapat menyeimbangkan emosi, kesan santai, dan ramah lingkungan), hitam (elegan), putih sebagai warna tambahan/kombinasi karena jika warna putih terlalu dominan akan menyebabkan rasa sakit kepala dan mata lelah, dan warna coklat yang memberi kesan nyaman, aman, modern, canggih, dan kuat (Zharandont, 2013).

Salah satu cara yang dapat dilakukan agar setrika dapat menghemat listrik adalah adanya tombol pengatur suhu (Donna, 2016). Dengan adanya pengatur suhu, pengguna dapat menyesuaikan panas yang diiginkan sesuai dengan bahan pakaian dan kecepatan dalam menyetrika. Selain itu, dengan adalah sistem otomatis pengatur suhu ini, setrika akan memberikan kode dengan matinya lampu yang ada pada setrika sebagai tanda bahwa panas sudah mencapai titik maksimal.

Konsep desain produk yang dilakukan oleh Wee (2014) mengembangkan setrika pada desain luar setrika yang memiliki 2 sisi simetris, yaitu bagian depan memiliki bentuk yang sama dengan bagian belakang. Wee mendesain setrika agar pengguna tidak perlu memutar atau mengubah arah pergerakkan setrika sehingga pengguna bebas menggunakan kedua tangannya saat memegang setrika serta tidah perlu bingung dalam menentukan arah menyetrika. Dengan desain tersebut, pengguna dapat mengurangi gerakan dalam mengangkat setrika yang memiliki kemungkinan dapat melukai pengguna atau menimbulkan cidera.

Pada penelitian ini, aspek ergonomi, keselamatan kerja, dan biaya menjadi pertimbangan dalam menentukan bagian/komponen pada setrika listrik. Aspek ergonomi digunakan sebagai dasar merancang gagang setrika agar nyaman saat digenggam. Aspek keselamat kerja menjadi dasar pada desain setrika yang dapat digerakkan menggunakan pegas sehingga alas setrika hanya akan keluar jika mendapatkan tekanan dari pengguna. Sedangkan aspek biaya digunakan pada pemilihan sistem pengatur suhu serta pemilihan bahan pada kerangka setrika.

Dari seluruh perbaikan desain tersebut, perbaikan yang memiliki manfaat terbesar adalah kemanan pada penghantar panas. Diharapkan dengan sistem ini dapat mengurangi tingkat kecelakaan kerja akibat pengoperasian setrika listrik. Cara kerja pada bagian ini yaitu pada posisi normal atau tidak digunakan dan tidak diberi tekanan, posisi alas setrika akan berada menggantung di dalam setrika. Saat setrika dalam keadaan menyala/panas dan sedang tidak digunakan, jika setrika mengenai pengguna maka tidak akan terjadi cidera. Sedangkan jika diberi tekanan dengan cara meletakkan setrika pada bidang datar lalu diberi tekanan pada gagang setrika, maka alas penghantar panas akan turun atau keluar dari posisi semula/posisi normalnya. Dengan demikian, setrika hanya akan berfungsi pada saat yang dibutuhkan, dan alas penghantar panas hanya akan mengenai objek yang diinginkan. Gambar 3 adalah hasil akhir desain setrika tersebut.

Pada saat tidak ada tekanan atau disebut saat relax, pegas di dalam kerangka setrika juga berada pada kondisi normal, sehingga alas penghantar panas akan berada di dalam atau tersembunyi di dalam kerangka setrika. Gambar 4 menunjukkan posisi setrika saat mendapat tekanan. Pada saat diberi tekanan, pegas pada kerangka setrika menjadi rapat, sehingga alas penghantar panas pada kerangka setrika akan menurun dan keluar dari kerangka setrika. Alas penghantar panas akan berada sejajar dengan kerangka luar pada setrika. Pada posisi ini, setrika siap untuk digunakan.

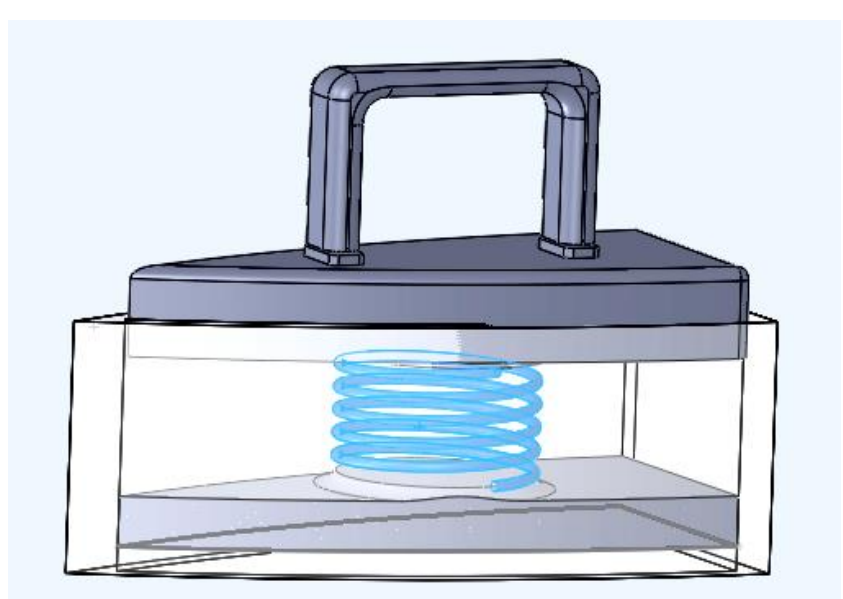

Gambar 3. Desain Setrika Posisi Relax

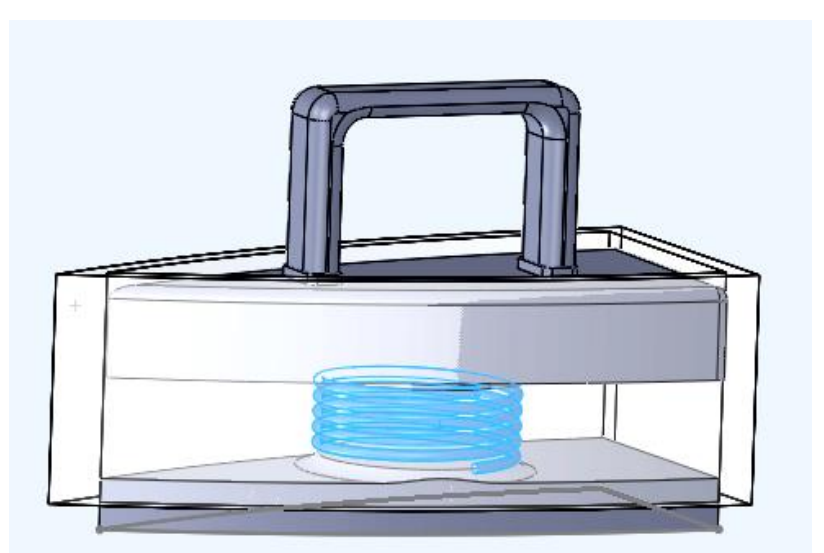

Gambar 4. Desain Setrika Posisi Ditekan

\section{Hasil Validasi Desain}

Untuk menguji ada tidaknya perbedaan antara desain setrika listrik yang telah beredar di pasaran dengan desain setrika pegas pada penelitian ini, dilakukan 


\section{TEKNIK, 39 (1), 2018, 10}

validasi statistik menggunakan uji homogenitas Stuart Maxwell Marginal (Soewardi, 2015). Hipotesis yang digunakan adalah:

$\mathrm{H}_{0}$ : Tidak ada perbedaan yang signifikan antara desain setrika yang telah beredar di pasaran dengan desain setrika pegas

$\mathrm{H}_{1}$ : Ada perbedaan yang signifikan antara desain setrika yang telah beredar di pasaran dengan desain setrika pegas.

Penilaian ada tidaknya perbedaan antara produk terdahulu dengan produk yang akan dikembangkan dilakukan dengan menyebarkan kuestioner kepada responden yang sama saat mencari Voice of Customer. Responden diperlihatkan gambar desain beserta fitur, manfaat, dan cara kerja setrika yang telah didesain. Responden kemudian diminta mengisi kuestioner tentang ada tidaknya pererbedaan antara desain setrika yang sudah ada di pasaran dengan desain baru ini. Hasil dari kuesioner diolah dengan menggunakan software SPSS. Hasil pengujian dengan Stuart Maxwell Marginal ditampulkan dalam Tabel 4.

Tabel 4. Pengujian Stuart Maxwell Marginal

\begin{tabular}{lc}
\hline \multicolumn{1}{c}{ Atribut } & Nilai Z \\
\hline Aman & 0.319 \\
Gagang nyaman digenggam & 0.517 \\
Tahan Lama & 0.329 \\
Ringan & 0.991 \\
Kesesuaian warna & 0.812 \\
Hemat Listrik & 0.963 \\
\hline
\end{tabular}

Tabel 4 menyajikan hasil pengujian Stuart Maxwell dengan nilai $\mathrm{z}$ yang berada pada range 0.319 hingga 0.991. Seluruh nilai $\mathrm{z}>0.05$ maka dapat disimpulkan bahwa seluruh atribut/parameter desain setrika pegas dinyatakan valid untuk digunakan sebagai kriteria yang diinginkan konsumen.

\section{Kesimpulan}

Konsep desain setrika listrik menggunakan metode Kano menghasilkan setrika yang aman digunakan yaitu dengan sistem alas setrika yang dapat digerakkan, gagang yang nyaman digenggam dengan mengacu pada desin yang ergomis, tahan lama dan ringan dengan menggunakan material ebonite dan aluminium sebagai kerangka setrika, kesesuaian warna yang digunakan tidak mencolok dan sesuai dengan psikologi manusia, dan setrika yang hemat listrik dengan menggunakan kontrol suhu otomatis.

\section{Daftar Pustaka}

Donna, A. (2016). Tips Memakai Setrika yang hemat Listrik. Diakses dari http://www.suara.com/bisnis/2016/03/05/081022/ti ps-memakai-setrika-yang-hemat-listrik

Dwirini, E., Rohayati, Y., \& Fashanah, A. (2015). Analisa Kebutuhan Produk Dodol Guavagua Menggunakan Integrasi Model Kano dan Product Quality Di UKM Barakah Alam Ciwidey. Proceeding of Engineering, 2(2), 4070-4077..

Haryono, M., \& Bariyah, C. (2014). Perancangan Konsep Produk Alas Kaki dengan Menggunakan Integrasi Metode Kansei Engineering dan Model Kano. Jurnal Ilmiah Teknik Industri, 13 (1), 71-82.

Lazuardy, H. (2013). Indonesia Pimpin Pasar Elektronika Rumah Tangga ASEAN. Diakses dari http://gadget.bisnis.com/read/20130810/282/15598 2/indonesia-pimpin-pasar-elektronika-rumahtangga-asean, tanggal 10 Agustus 2013.

Liu, H. (2012). Research on Module Selection Method Based on the Integrating of Kano Module with QFD Method. Journal of Service Science and Management. 5, 206-211.

Mardani, M.I. (2015). Asal-usul sejarah Setrika. Diakses dari

http://www.kompasiana.com/iskandarmardani/asalusul-sejarah-setrika 5500f225a33311e77251293e.

Metal Supermarket. (2014). 10 differences between aluminum and stainless steel. Diakses dari https://www.metalsupermarkets.com/10differences-aluminum-stainless-steel/

Paraschivescu, A.O. (2012). Kano Model. Economic Transdiciplinarity Cognition. 15, 116-124.

Purnomo, H. (2014). Pengukuran Antropometri Tangan Usia 18 Sampai 22 Tahun Kabupaten Sleman Yogyakarta. Seminar Nasional Industrial Engineering National Conference.

Rashid, M.M., Tamaki, J., Ullah, S., \& Kubo, A. (2011). A Kano Model Based Linguistic Application for Customer Need Analysis. International Journal of Engineering Business Management. 3(2), 29-36.

Rubber Santo, PT. (2017). Karet Ebonit. Diakses dari http://www.industrikaret.com/karet-ebonit.html

Soewardi, H., Ajie, B.T., \& Jalal, R.A. (2015). Inovative Design of Wheelchair By Using User Centered Design Approach. Proceeding $8^{\text {th }}$ International Seminar on Industrial Engineering and Management.

Standar Nasional Indonesia. (2005). Piranti Listrik Rumah Tangga dan Sejenis - Keselamatan - Bagian 2-3 : Persyaratan Khusus untuk Setrika Listrik.

Taifa, I.W., \& Desai, D.A. (2016). Student Defined Quality by Kano Model : A Case Study Of Engineering Students in India. International Journal for Quality Research. 10(3), 569-582.

Wee, L. K. (2014). Enhancing the User Experince of Using an Electric Iron. Diakses dari 


\section{TEKNIK, 39 (1), 2018, 10}

https://pdfs.semanticscholar.org/633c/534ad7b5c0f e4d06ec9459c11af0076e3d27.pdf

Zharandont, P.( 2013). Pengaruh Warna bagi Suatu roduk dan Psikologis Manusia. Diakses dari http://www.academia.edu/19675069/JURNAL_ER
GONOMI PENGARUH WARNA BAGI_SUAT

U_PRODUK_DAN_PSIKOLOGIS_MANUSIA 